\section{Commentary: You mean there are 89 others?}

\author{
Charles B. Huddleston, MD, and
}

Andrew C. Fiore, MD

The dilemma of donor shortage to supply the ongoing and increasing needs of organ transplantation has been a concern since early in the transplant experience. ${ }^{1}$ Much effort has been made to increase the donor pool, such as questioning people at the time of driver's license applications, media advertising using celebrities, and legislation. In fact, the number of heart donors in the United States has increased over the past 30 years from nearly 2200 to 3600 annually. Unfortunately, however, the number listed for heart transplantation during that same time period has grown from 3000 to $4700 .^{2}$ This has created an overall shortfall of approximately 1000 patients per year (Figure 1). If heart transplantation were a business (well, I suppose it actually is, if you look at hospital revenues), the donor shortage issue would clearly be the most obvious limitation to business success.

One avenue to increase the donor pool is to use DCD (donation following circulatory death) donors. Although DCD donors have been used for other solid organ transplants for many years, there has been considerable reluctance on the part of heart transplantation centers to use this resource and with good reason-how can one reasonably expect a heart to work when the cause of death is basically a dead heart? Nonetheless, the potential increase in available donors if this source were made available is significant. Some centers have been actively using DCD donors for heart transplantation. In the largest series published to date, Chew and colleagues ${ }^{3}$ describe 23 transplants from DCD donors, with 1 postoperative death. In this study

\footnotetext{
From the Division of Cardiothoracic Surgery, St Louis University School of Medicine, St Louis, Mo.

Disclosures: All authors reported no conflicts of interest.

The Journal policy requires editors and reviewers to disclose conflicts of interest and to decline handling or reviewing manuscripts for which they may have a conflict of interest. The editors and reviewers of this article have no conflicts of interest.

Received for publication March 31, 2020; accepted for publication March 31, 2020; available ahead of print April 18, 2020.

Address for reprints: Charles B. Huddleston, MD, 1465 S Grand Blvd, St, Louis, MO 63104 (E-mail: Charles.huddleston@ health.slu.edu).

J Thorac Cardiovasc Surg 2022;163:e199-200

$0022-5223 / \$ 36.00$

Copyright (c) 2020 by The American Association for Thoracic Surgery

https://doi.org/10.1016/j.jtcvs.2020.03.151
}

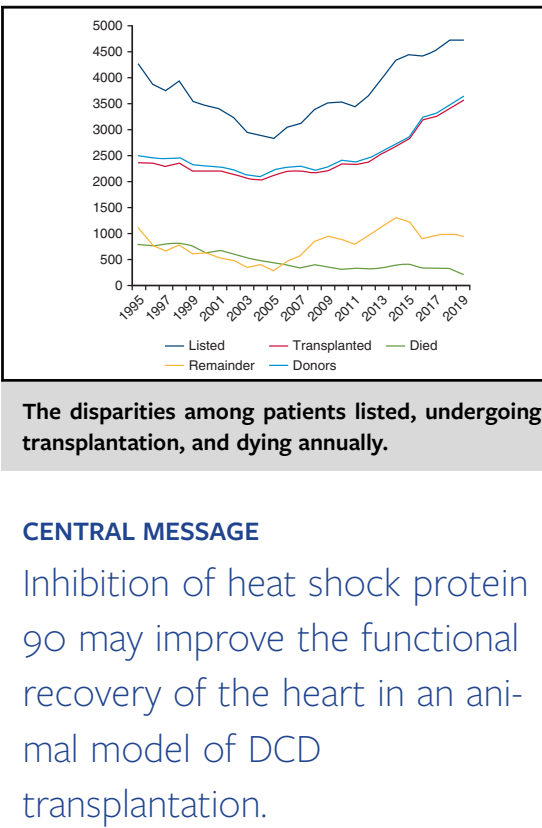

from Australia, the hearts were placed on a normothermia perfusion device, and viability was assessed by measuring serial lactate levels and hemodynamic parameters and observing ventricular function. Although survival was quite good, a significant number of recipients required mechanical support early post-transplantation. This underscores the need for further research into improving DCD donor hearts.

In this issue of the Journal, Aceros and colleagues ${ }^{4}$ describe an animal model of DCD donation in which cardiac function appears to be maintained using an inhibitor of heat shock protein (HSP) 90. HSPs are ubiquitous and primarily intracellular and are known as "molecular chaperones," in that they ensure that other intracellular proteins are functional. Admittedly, this is an oversimplification of their role. Unfortunately, HSPs may enhance cell function in a somewhat selfdestructive fashion for the organ or organism as a whole in response to stress, inflammation, ischemia/reperfusion injury, or tumor growth. The "normal" cellular response to these stressors might not be beneficial to the organ or organism.

In the animal study reported by Aceros and colleagues, the DCD model used involved a 15-minute warm ischemic time, followed by administration of cardioplegia with the HSP90 inhibitor, followed by 10 minutes of stabilization using the Langendorff preparation and then assessment over the subsequent 60 minutes. Whether this accurately reflects what really occurs with 


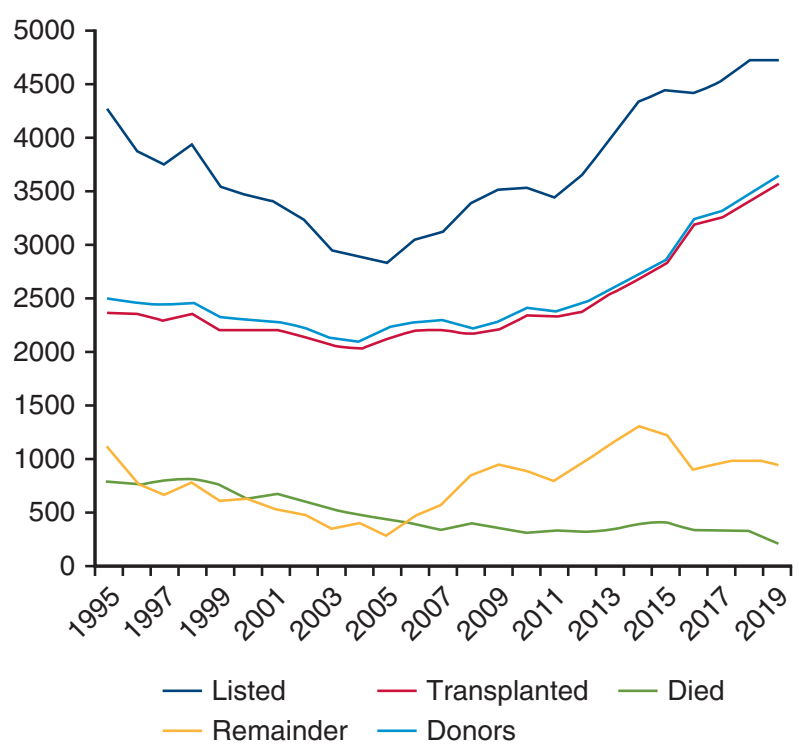

FIGURE 1. The disparities among patients listed, undergoing transplantation, and dying annually.

DCD procedures is questionable, but it appeared to induce a measurable injury. The use of an HSP90 inhibitor substantially mitigated that injury.
Research on HSPs has been ongoing for many years, and some clinical studies are currently in process, particularly in cancer and autoimmunity treatments. Because HSPs are present in all cells, it is not clear what modulating their impact might be when given systemically. There is some appeal of a model such as this, in which only the heart receives the drug inhibiting HSP90 function. Whether or not the use of HSP90 inhibitors for DCD donors (or even brain-dead donors) is effective in humans, this study expands the possibility of using this donor pool to serve the needs of the ever-growing population of patients awaiting heart transplantation. I just wish I knew something about the other 89 HSPs.

\section{References}

1. Evans RW, Manninen DL, Garrison LP, Maier AM. Donor availability as the primary determinant of the future of heart transplantation. JAMA. 1986;255:1892-8.

2. US Department of Health and Human Services. Organ Procurement and Transplantation Network. National data. Available at: https://optn.transplant.hrsa.gov/ data/view-data-reports/national-data/. Accessed April 21, 2020.

3. Chew HC, Iyer A, Connellan M, Scheuer S, Villanueva J, Gao L, et al. Outcomes of donation after circulatory death heart transplantation in Australia. J Am Coll Card. 2019;73:1447-59.

4. Aceros H, Borie M, Ribeiro RVP, Stevens LM, Maltais S, Der Sarkissian S, et al. Novel heat shock protein 90 inhibitor improves cardiac recovery in a rodent model of donation after circulatory death. J Thorac Cardiovasc Surg. 2022;163: e187-97. 